NASA/TM-2002-211733

ARL-TR-2735
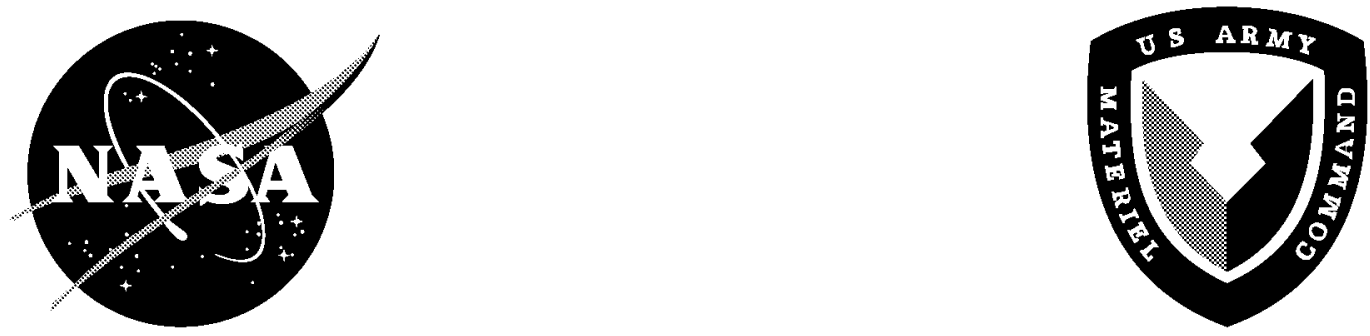

\title{
Occupant Responses in a Full-Scale Crash Test of the Sikorsky ACAP Helicopter
}

Karen E. Jackson, Edwin L. Fasanella, and Richard L. Boitnott

U.S. Army Research Laboratory

Vehicle Technology Directorate

Langley Research Center, Hampton, Virginia

Joseph McEntire and Alan Lewis

U.S. Army Aeromedical Research Laboratory

Fort Rucker, Alabama 


\section{The NASA STI Program Office ... in Profile}

Since its founding, NASA has been dedicated to the advancement of aeronautics and space science. The NASA Scientific and Technical Information (STI) Program Office plays a key part in helping NASA maintain this important role.

The NASA STI Program Office is operated by Langley Research Directorate, the lead Directorate for NASA's scientific and technical information. The NASA STI Program Office provides access to the NASA STI Database, the largest collection of aeronautical and space science STI in the world. The Program Office is also NASA's institutional mechanism for disseminating the results of its research and development activities. These results are published by NASA in the NASA STI Report Series, which includes the following report types:

- TECHNICAL PUBLICATION. Reports of completed research or a major significant phase of research that present the results of NASA programs and include extensive data or theoretical analysis. Includes compilations of significant scientific and technical data and information deemed to be of continuing reference value. NASA counterpart of peerreviewed formal professional papers, but having less stringent limitations on manuscript length and extent of graphic presentations.

- TECHNICAL MEMORANDUM. Scientific and technical findings that are preliminary or of specialized interest, e.g., quick release reports, working papers, and bibliographies that contain minimal annotation. Does not contain extensive analysis.

- CONTRACTOR REPORT. Scientific and technical findings by NASA-sponsored contractors and grantees.
- Conference publication. Collected papers from scientific and technical conferences, symposia, seminars, or other meetings sponsored or co-sponsored by NASA.

- SPECIAL PUBLICATION. Scientific, technical, or historical information from NASA programs, projects, and missions, often concerned with subjects having substantial public interest.

- TECHNICAL TRANSLATION. Englishlanguage translations of foreign scientific and technical material pertinent to NASA's mission.

Specialized services that complement the STI Program Office's diverse offerings include creating custom thesauri, building customized databases, organizing and publishing research results ... even providing videos.

For more information about the NASA STI Program Office, see the following:

- Access the NASA STI Program Home Page at http://www stinasa.gov

- E-mail your question via the Internet to help@stinasa.gov

- Fax your question to the NASA STI Help Desk at (301) $621-0134$

- Phone the NASA STI Help Desk at (301) 621-0390

- Write to:

NASA STI Help Desk NASA Directorate for AeroSpace Information 7121 Standard Drive Hanover, MD 21076-1320 
NASA/TM-2002-211733

ARL-TR-2735
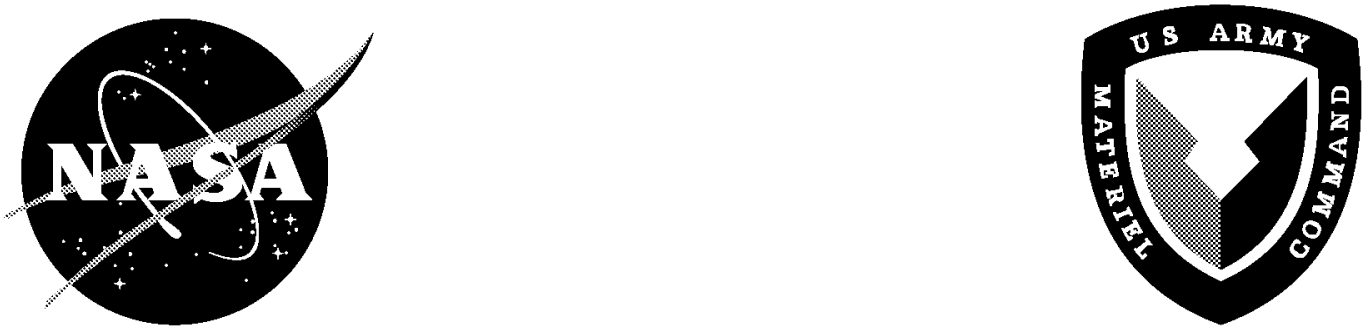

\section{Occupant Responses in a Full-Scale Crash Test of the Sikorsky ACAP Helicopter}

Karen E. Jackson, Edwin L. Fasanella, and Richard L. Boitnott

U.S. Army Research Laboratory

Vehicle Technology Directorate

Langley Research Center, Hampton, Virginia

Joseph McEntire and Alan Lewis

U.S. Army Aeromedical Research Laboratory

Fort Rucker, Alabam

National Aeronautics and

Space Administration

Langley Research Center

Hampton, Virginia 23681-2199

June 2002 
The use of trademarks or names of manufacturers in the report is for accurate reporting and does not constitute an official endorsement, either expressed or implied, of such products or manufacturers by the National Aeronautics and Space Administration or the U.S. Army.

Available from:

NASA Center for AeroSpace Information (CASI) 7121 Standard Drive

Hanover, MD 21076-1320

(301) 621-0390
National Technical Information Service (NTIS)

5285 Port Royal Road

Springfield, VA 22161-2171

(703) $605-6000$ 


\title{
Occupant Responses in a Full-Scale Crash Test of the Sikorsky ACAP Helicopter
}

\author{
Karen E. Jackson, Edwin L. Fasanella, and Richard Boitnott \\ k.e.jackson@larc.nasa.gov, e.l.fasanella@larc.nasa.gov, r.l.boitnott@larc.nasa.gov \\ US Army Research Laboratory, Vehicle Technology Directorate \\ Hampton, Virginia \\ Joseph McEntire and Alan Lewis \\ Joe.Mcentire@se.amedd.army.mil, alan.lewis@se.amedd.army.mil \\ US Army Aeromedical Research Laboratory \\ Ft. Rucker, Alabama
}

\begin{abstract}
A full-scale crash test of the Sikorsky Advanced Composite Airframe Program (ACAP) helicopter was performed in 1999 to generate experimental data for correlation with a crash simulation developed using an explicit nonlinear, transient dynamic finite element code. The airframe was the residual flight test hardware from the ACAP program. For the test, the aircraft was outfitted with two crew and two troop seats, and four anthropomorphic test dummies. While the results of the impact test and crash simulation have been documented fairly extensively in the literature, the focus of this paper is to present the detailed occupant response data obtained from the crash test and to correlate the results with injury prediction models. These injury models include the Dynamic Response Index (DRI), the Head Injury Criteria (HIC), the spinal load requirement defined in FAR Part 27.562(c), and a comparison of the duration and magnitude of the occupant vertical acceleration responses with the Eiband whole-body acceleration tolerance curve.
\end{abstract}

\section{Introduction}

In 1999, a full-scale crash test of a prototype composite helicopter was performed at the Impact Dynamics Research Facility (IDRF) that is located at NASA Langley Research Center in Hampton, VA. The IDRF is a $240-\mathrm{ft}$. high gantry structure that has been used for conducting full-scale crash tests of light aircraft and rotorcraft since the early 1970's [1]. The helicopter was the flight test article built by Sikorsky Aircraft under sponsorship by the U.S. Army during the Advanced Composite Airframe Program (ACAP). The purpose of the ACAP was to demonstrate the potential of advanced composite materials to save weight and cost in airframe structures while achieving systems compatibility and meeting Army requirements for vulnerability, reliability, maintainability, and survivability. In 1981, the US Army awarded separate contracts to Bell Helicopter Textron and Sikorsky Aircraft Corporation to design and fabricate helicopters constructed primarily of advanced composite materials. Each company manufactured three airframes, and one helicopter airframe from each company was equipped to become a flying prototype. Crash tests of the Bell and Sikorsky
ACAP static test articles were conducted in 1987 at the NASA IDRF by the US Army to demonstrate their crash performance [2, 3].

In 1997, the US Army Aviation Applied Technology Directorate (AATD) established a Science and Technology Objective (STO) in crash modeling and simulation. The Army Research Laboratory's Vehicle Technology Directorate (ARL-VTD) was selected by AATD as the primary performing organization for the STO. The purpose of the STO was to establish a standardized and validated structural crash dynamics modeling and simulation capability from a commercial computer code that would satisfy the need for a crashworthy performance and design evaluation tool. As part of the STO, a full-scale crash test of the Sikorsky ACAP residual flight test article was planned to generate experimental data for correlation with the crash simulation. In 1998, AATD cancelled the STO; however, the original plans for the crash test and model validation were continued under the support of the NASA Aviation Safety Program [4]. For the test, the aircraft was outfitted with two crew and two troop seats, and four anthropomorphic test dummies. The crash simulation 
was performed using the nonlinear, explicit transient dynamic code MSC.Dytran [5], and the results of the validation study have been published in References 6 through 9. Experimental results from the crash test have been reported in Reference 10 including the crash sequence of events, an assessment of structural deformation and fuselage damage, and the dynamic response of the airframe and large mass items such as the engines and rotor transmission. The seat damage was described fairly extensively; however, only a limited amount of occupant response data was reported.

The objectives of this paper are to present the occupant test data obtained during the full-scale crash test of the Sikorsky ACAP helicopter and to correlate the results with injury prediction models. These models include the Dynamic Response Index (DRI), the Head Injury Criteria $(H I C)$, the spinal load requirement defined in FAR Part 27.562 (c), and a comparison of occupant vertical acceleration responses with the Eiband whole-body acceleration tolerance curve.

\section{Full-Scale Crash Test}

Pre- and post-test photographs of the Sikorsky ACAP helicopter are shown in Figure 1. The planned test conditions were 38 -ft/s vertical and 32.5 -ft/s horizontal velocity, with $5^{\circ}$ nose-up pitch and no yaw or roll angle. The measured impact conditions were 38-ft/s vertical and 32.5$\mathrm{ft} / \mathrm{s}$ horizontal velocity, with $6.25^{\circ}$ nose-up pitch and $3.5^{\circ}$ left-down roll. Also, a $9.6^{\circ} /$ second nose-up pitch angular velocity was induced as a result of the pendulum-swing drop test procedure $[10,11]$. During the crash test, over eighty channels of data were acquired at 10,000 samples per second using a 12-bit resolution digital data acquisition system (DAS).

\section{Right and Left Crew Dummies and Seats}

A 50th percentile male Hybrid II anthropomorphic test dummy, weighing approximately 170-lbs., was used to represent the pilot in the right front crew position. The dummy was instrumented with tri-axial accelerometers located in the head, chest, and pelvis. A lumbar load cell was installed to measure the spinal compressive force response. Additional load cells were used to measure the force in the lap and shoulder belts. The pilot was placed in a used commercial military-qualified helicopter seat provided by the US Army Aeromedical Research Laboratory (USAARL). This seat contained two invertube energy absorbers. New MA-16 inertia locking reels were used with lap and shoulder belts to restrain the dummy occupant during the test. Accelerometers were mounted to the seat pan to measure forward and vertical acceleration responses. Tri-axial accelerometers were located on the floor near the pilot seat attachment to the outboard seat rail.

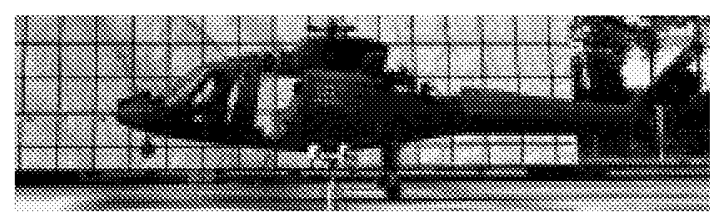

(a) Pre-test photograph.

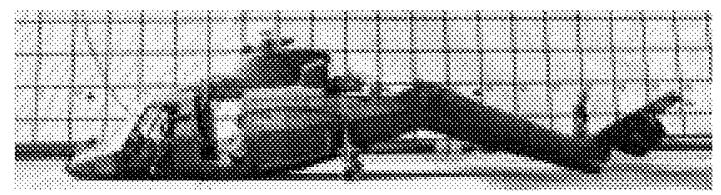

(b) Post-test photograph.

Figure 1. Pre- and post-test photographs of the Sikorsky ACAP helicopter.

The USAARL supplied a fully instrumented modified Hybrid III 50th percentile dummy with a self-contained DAS for the left front crew (copilot). This dummy weighed approximately 198-lbs. and was the only dummy to be outfitted with a helmet for the test. The modifications to the dummy included the incorporation of an EME Corp. internal data acquisition system. In addition, the rigid spine box of the Hybrid III was replaced with a flexible spine consisting of rubber disc segments between each rib as well as two torsional joints. The head of the Hybrid III dummy was replaced with a Hybrid II head because of the more representative anthropometry features and helmet fit compatibility.

Data collected for the copilot dummy using the self-contained DAS included head accelerations in three directions; T-1 thoracic accelerations in three directions; head pitch rate; C-1 cervical head/neck forces and moments; T-1 thoracic forces and moments; torso sternum accelerations in two directions; and lumbar forces and moments. The T-1 thoracic accelerometers were located at the base of the neck, and the torso sternum accelerometers were located in the front of the chest. In all, 29 channels of data 
were collected at 10,000 samples/second using the self-contained DAS, including three additional accelerometers to record tri-axial floorlevel accelerations. These accelerometers were located slightly behind and between the crew seats.

The copilot dummy was secured in a used commercial military-qualified helicopter seat of a different design than the pilot seat. This seat contained six "torshock" energy absorbers. Likewise, an MA-16 inertia locking reel was used in conjunction with the restraint system to limit the displacement of the dummy occupant during the test. Two accelerometers were mounted to the seat pan to measure forward and vertical accelerations, and tri-axial accelerometers were located on the floor near the copilot seat attachment to the outboard seat rail. Load cells were installed to measure lap and shoulder belt forces. Because the fore-aft adjusting pins for the crew seats used in this test were located at the front leg, holes were drilled in the front rail at the average longitudinal location. The seats were also adjusted to the middle vertical positions to allow a maximum vertical stroke of approximately 14.5 inches. The seat pan would contact the flexible seat well floor at a stroke of 13.5 inches.

Following the test, measurements were made indicating that the pilot seat stroked approximately 9 inches of the total 14.5 inches available. It was determined that the outboard pin attaching the pilot seat to the seat rail was either not properly engaged in the seat rail hole or disengaged during the impact. Without the outboard pin restraint, the seat rotated inward about the remaining inboard pin and the seat pan struck the front seat well frame instead of stroking down into the well. A post-test photograph of the pilot dummy is shown in Figure 2(a). The final position of the pilot seat is shown in Figure 2(b). The pin moved approximately 4 inches forward of its original location.

A post-test photograph of the copilot dummy and left crew seat is shown in Figure 3. During post-test examination of the copilot, a fragment of cloth was found on the right side of the dummy's forehead indicating contact with the knee. This discovery provides evidence that the natural slack in the restraint system allowed the dummy's head to rotate over and eventually strike its knee. The MA-16 inertia reels were not manually locked before the test. After the test both inertia reels were found to be locked. The copilot seat essentially "bottomed out" with approximately 14.5 inches of stroke. Post-test visual inspection of the seat indicated that the seat pan accelerometer punched through the flexible seat well floor.

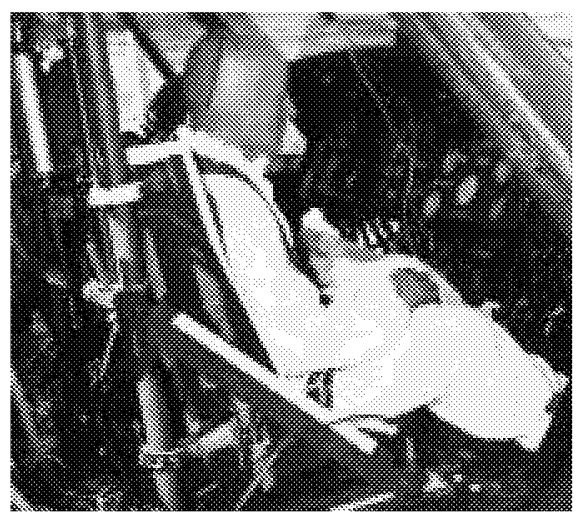

(a) Pilot dummy

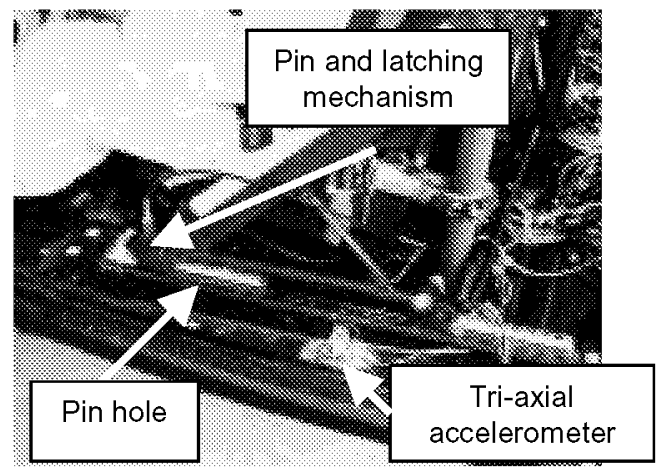

(b) Forward motion of the unpinned pilot seat.

Figure 2. Post-test photographs of the pilot (right crew) and seat.

The filtered vertical acceleration timehistories of the pilot floor, seat pan, and chest are given in Figure 4(a). The data were filtered using a 2-pole Butterworth low-pass digital filter with a cut-off frequency of $60-\mathrm{Hz}$. The data were filtered both forward and backward in time to eliminate any phase shift. The same lowpass digital filter was used to filter the test data shown in all of the plots in this paper, except where noted. The pilot's energy absorbing seat reduced the vertical acceleration peak from 93-g on the floor to approximately $40-\mathrm{g}$ at the seat pan. The chest acceleration peak is slightly lower at $36 \mathrm{-g}$ and is delayed in time by $.01 \mathrm{sec}-$ onds. Likewise, the filtered vertical acceleration time-histories for the copilot floor, seat pan, and 
chest (torso sternum) are plotted in Figure 4(b). The copilot's energy absorbing seat reduced the vertical acceleration peak from 85.6-g on the floor to approximately $33-g$ at the seat pan. The chest acceleration peak is of the same magnitude as the seat pan response, but is delayed in time. Thus, both the pilot and copilot seats reduced the floor-level acceleration peak by $53-\mathrm{g}$.

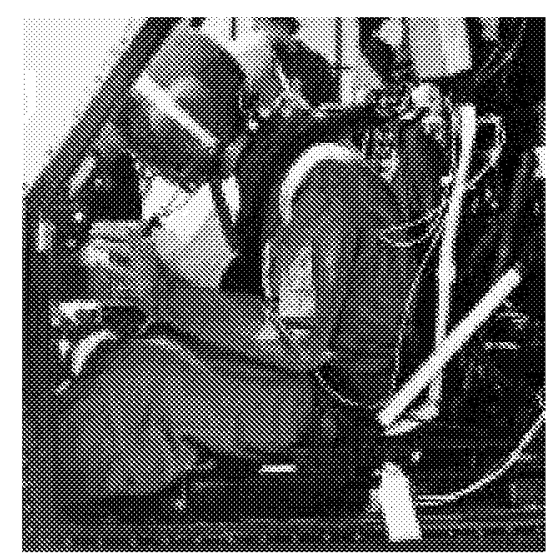

Figure 3. Post-test photograph of the copilot (left crew) dummy.

The crew seat pan accelerations are higher than desired for occupant survivability. A factor that likely contributed to the high seat pan acceleration responses was the fact that the original energy absorbing nose gear designed for the Sikorsky ACAP helicopter was not available for this test. Instead, a standard noncrashworthy commercial nose gear was retrofitted to provide a nominal level of energy absorption. However, the retrofitted nose gear could only absorb a small percentage of the kinetic energy that the original gear was designed to dissipate.

\section{Right and Left Troop Dummies and Seats}

Ceiling-suspended troop seats, each with two wire-bender energy absorbers, were mounted in the rear cabin area. New wirebender energy absorbers were installed in the troop seats; however, these seats were used and the seating material was in poor condition. The seat pan consisted of a nylon mesh cloth that was worn and oil-stained. Two Hybrid II 50th percentile anthropomorphic dummies, each weighing approximately 170 -lbs., were used to represent the right and left troop occupants. Both dummies were instrumented with tri-axial accelerometers located in the chest. One accel- erometer was mounted to the rear frame of the seat, and two accelerometers were attached to the floor near the troop seats.

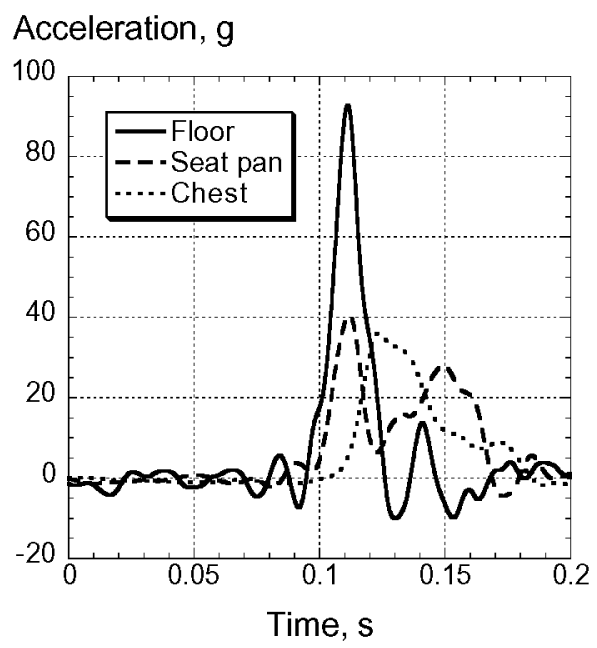

(a) Pilot acceleration responses.

\section{Acceleration, $g$}

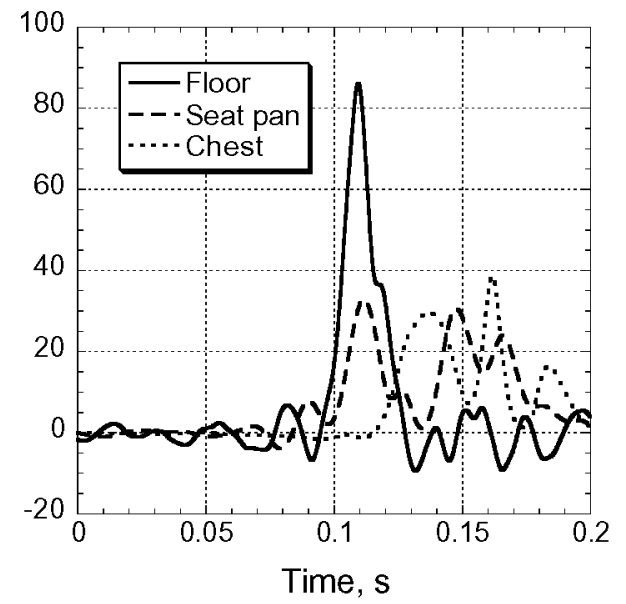

(b) Copilot acceleration responses.

Figure 4. Filtered vertical accelerations of the crew floor, seat pan, and pelvis.

Post-test photographs of the right and left troop occupants are shown in Figure 5. The seat pan cloth was torn in both troop seats, allowing the buttocks of both dummy occupants to displace downward through the seat frame. As a result, the wire-bender energy absorbers exhibited minimal stroking. The inboard wirebender of the left troop seat stroked approximately 1 inch while the displacements of the other wire-benders were considerably less. During impact, a large downward deflection of the helicopter's roof at the wire-bender suspen- 
sion location was observed in the high-speed film coverage. This roof deflection may have limited the stroking of the wire-bender mechanism, as well.

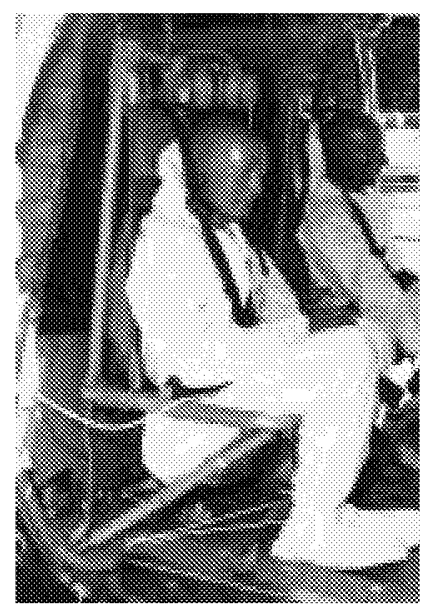

(a) Right troop.

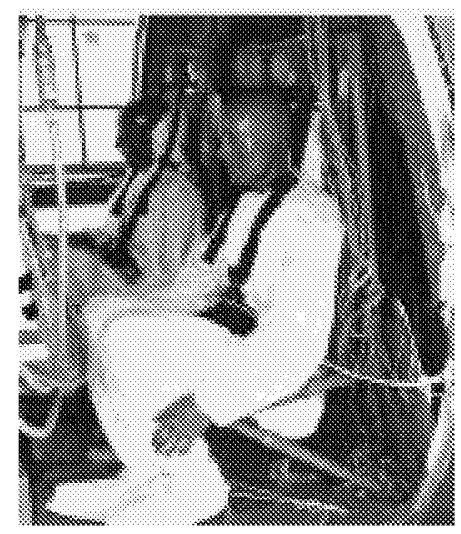

(b) Left troop.

Figure 5. Post-test photographs of the right and left troop occupants.

\section{Seat, Occupant, Restraint System, and Struc- tural Responses}

The unfiltered head acceleration time histories of the pilot and copilot dummies are plotted in Figure 6 in the forward, side, and vertical directions. Only the copilot forward head response is shown in Figure 6(a) due to anomalies in the pilot test data. The acceleration responses indicate that the copilot experienced a high-magnitude, short-duration spike at 0.188 seconds during the pulse, as a result of head strike. High-speed film coverage shows that at 0.188 seconds the copilot's head comes in contact with his knees. A head strike is further indicated by a bit of green flight suit fabric that was found embedded in the forehead of the dummy slightly above the right eyebrow. The dummy's head most likely contacted the right knee. The film shows the head still moving downward between the knees for an additional .017 seconds before rebounding upward. The spike at 0.188 seconds is observed in all three copilot head acceleration responses with peaks of 450-, 190-, and 42-g's in the forward, side, and vertical directions, respectively.

The filtered $\mathrm{T}-1$ thoracic acceleration responses of the copilot dummy are shown in Figure 7 for the forward, side, and vertical directions. The pilot dummy was not instrumented at this location; consequently, no comparison with the copilot test data is possible. The effect of the head strike experienced by the copilot dummy is evident in the large 48-g peak in the forward acceleration response shown in Figure 7 . In comparison, the vertical acceleration peak is $28 \mathrm{~g}$.

Plots of filtered vertical chest acceleration responses of the pilot and copilot, and the right and left troop dummies are shown in Figure 8. In general, the pilot and copilot dummies experienced higher peak accelerations than did the troop occupants. Plots of filtered chest acceleration responses of the pilot and copilot, and the right and left troop dummies are shown in Figure 9 in the forward direction. Again, the pilot and copilot experienced significantly higher peak acceleration responses than did the troop dummies.

The filtered acceleration responses of the pilot pelvis are shown in Figure 10 for the forward, side, and vertical directions. The copilot dummy was not instrumented with pelvic accelerometers; consequently, no comparison with the pilot test data is possible. As expected, the peak vertical acceleration $(40-g)$ is significantly higher than either the forward $(22-\mathrm{g})$ or side (13g) peak accelerations.

The filtered vertical seat pan acceleration responses of the pilot, copilot, and troop seats are shown in Figure 11. It should be noted that the data for the troop seats was obtained from accelerometers placed on the rear seat frame, since the troop seats contained a cloth seat pan. The acceleration pulse shapes are similar for the pilot and copilot seat pans and for the right and left troop seat frames, respectively. 
Acceleration, $g$

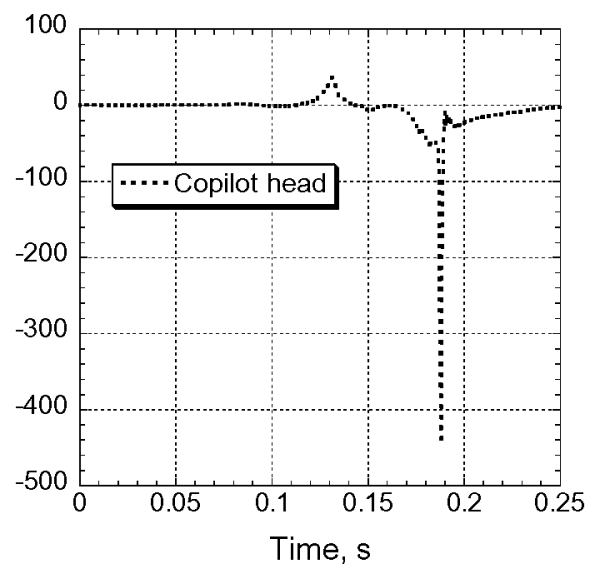

(a) Forward acceleration.

Acceleration, $\mathrm{g}$

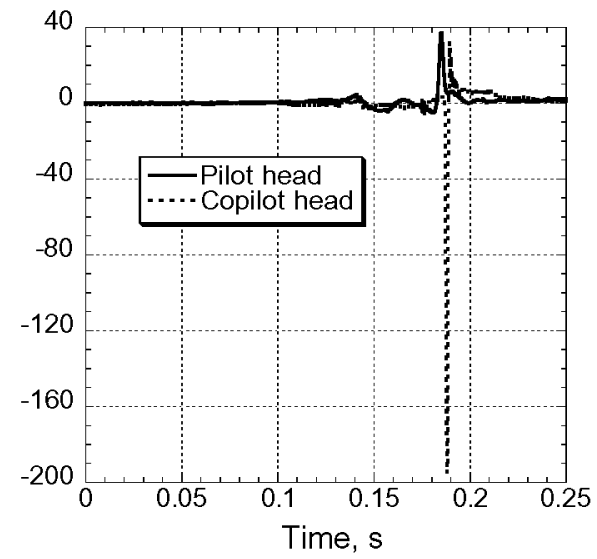

(b) Side acceleration.

Acceleration, $g$

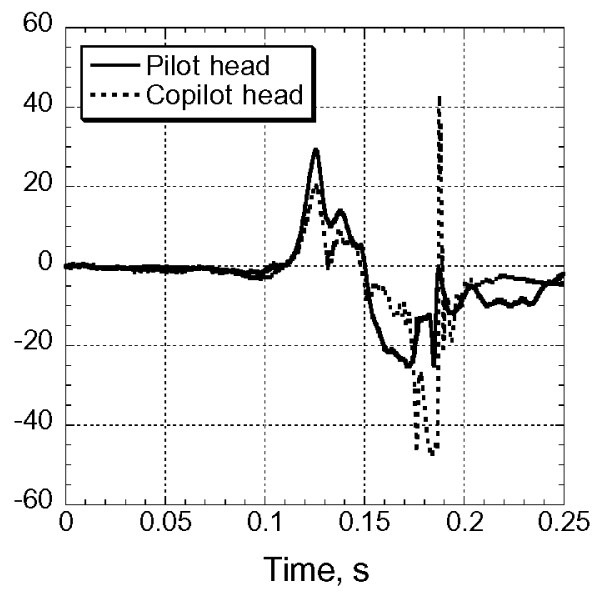

(c) Vertical acceleration.

Figure 6. Unfiltered pilot and copilot head acceleration responses in three directions.
Acceleration, $\mathrm{g}$

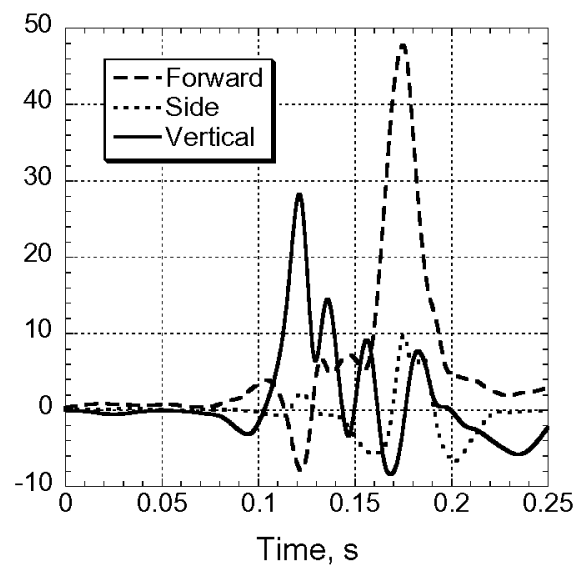

Figure 7. Filtered copilot $\mathrm{T}-1$ thoracic acceleration responses in three directions.

Acceleration, $\mathrm{g}$

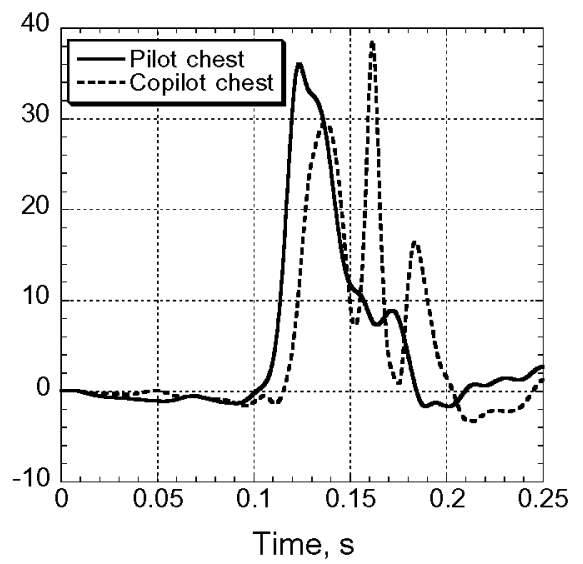

(a) Pilot and copilot.

Acceleration, $g$

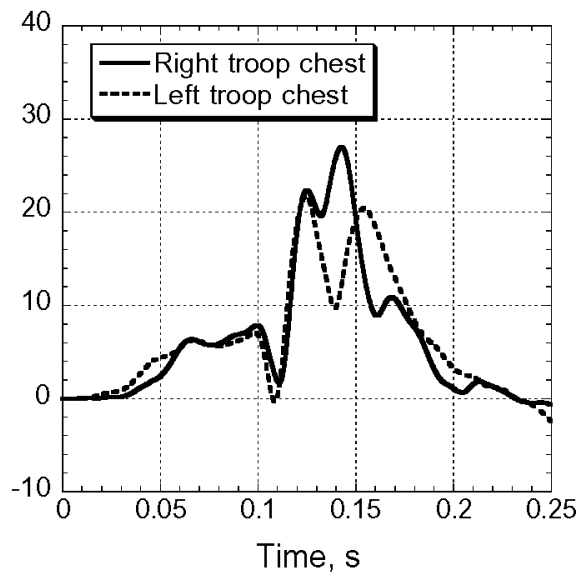

(b) Right and left troop.

Figure 8. Filtered vertical chest acceleration responses of four dummies. 


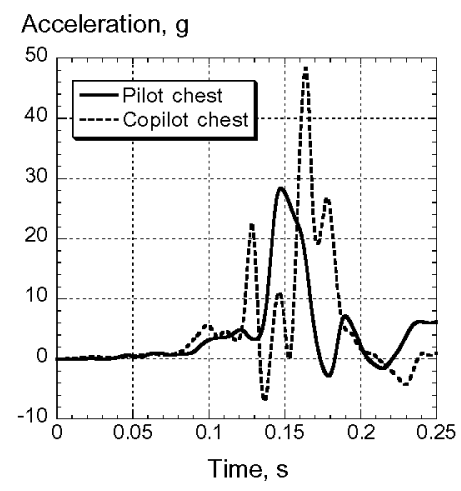

(a) Pilot and copilot chest.

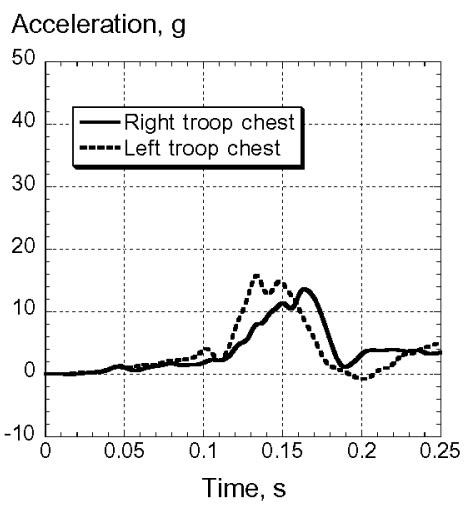

(b) Right and left troop chest.

Figure 9. Filtered forward chest acceleration responses of four dummies.

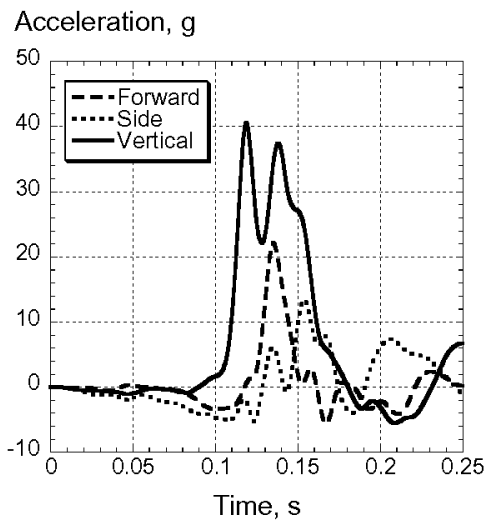

Figure 10. Pilot pelvis acceleration responses.

The restraint systems of both the pilot and copilot dummies were instrumented to measure lap and shoulder belt loads. These responses are plotted in Figure 12. Note that only the pilot shoulder belt response is shown in Figure 12 due to anomalies in the copilot test data. The FAR 27.562 (c) specifies that where upper torso straps are used for crew members, tension loads in individual straps must not ex- ceed 1,750 pounds, and, if dual straps are used for restraining the upper torso, the total strap tension loads must not exceed 2,000 pounds [12]. The restraint loads measured in the crew dummies did not exceed these limits. The troop restraint systems were not instrumented.

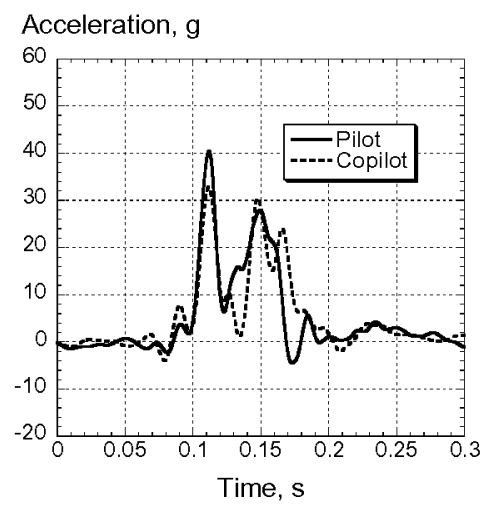

(a) Pilot and copilot.

Acceleration, $\mathrm{g}$

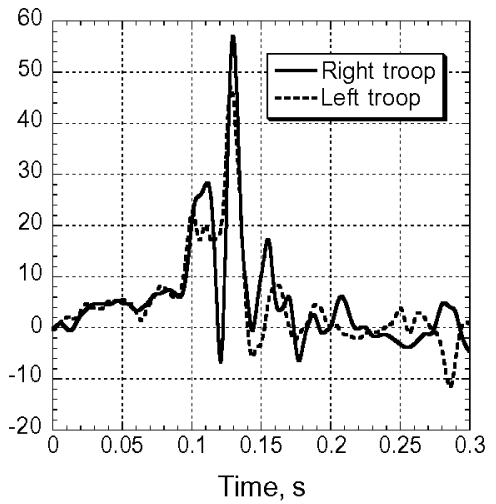

(b) Right and left troop.

Figure 11. Filtered seat pan vertical acceleration responses.

Accelerometers were installed to record floor-level acceleration responses in three directions using the self-contained DAS in the copilot dummy supplied by USAARL. In addition, floorlevel acceleration responses were measured near the outboard seat attachment points for the pilot and copilot using the NASA data acquisition system. The filtered acceleration responses for these three locations are shown in Figure 13. The similarity in the floor-level acceleration responses is surprising given that the accelerometers were not mounted in exactly the same location on the floor and the signals were recorded on two different data acquisition systems. These results provide confidence in the quality and validity of the experimental data. 
Force, Ibs.

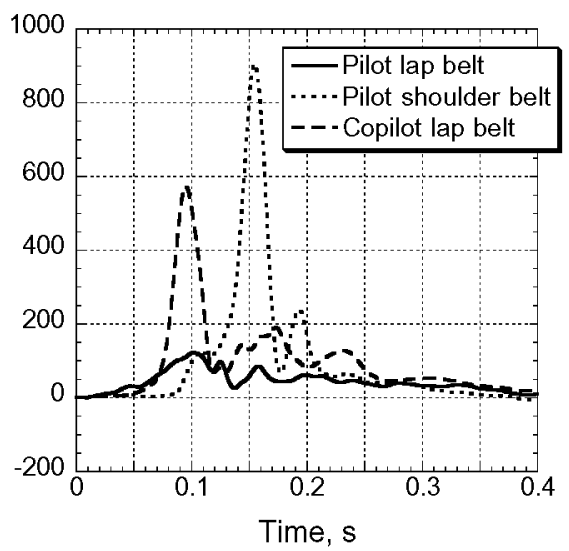

Figure 12. Filtered restraint system loads for the pilot and copilot.

\section{Injury Prediction}

\section{Dynamic Response Index (DRI)}

One commonly used injury prediction model is the Dynamic Response Index (DRI) [13]. The DRI is derived from a simple onedimensional lumped-mass spring damper system, as depicted in Figure 14. This model was developed by the Air Force's Wright Laboratory to estimate the probability of compression fractures in the lower spine due to acceleration in a pelvis-to-head direction, as might be experienced by aircrew during ejection seat operations. Unfiltered vertical acceleration responses of the seat pan of the pilot and copilot, and the right and left troop were used as input to compute the dynamic DRI.

The continuous DRI time histories for each occupant are shown in Figure 15. The maximum DRI values for the crew and troop dummies are noted in the legend descriptions in Figure 15 and they range from 22.3 to 30 . Operational data from actual ejection seat incidents indicate that the spinal injury rate for maximum DRI values between 20 and 23 range from 16 to 50 percent, see References 14 and 15.

Occupant acceleration data are compared with the continuous DRI responses in Figure 16. For the pilot, both the chest and pelvis vertical acceleration responses are compared with the DRI in Figure 16(a). For the copilot, the vertical acceleration response of the chest (torso sternum) is compared with the DRI in Figure 16(b). For the troop dummies, the vertical chest acceleration responses are compared with the DRI in Figures 16(c) and (d).

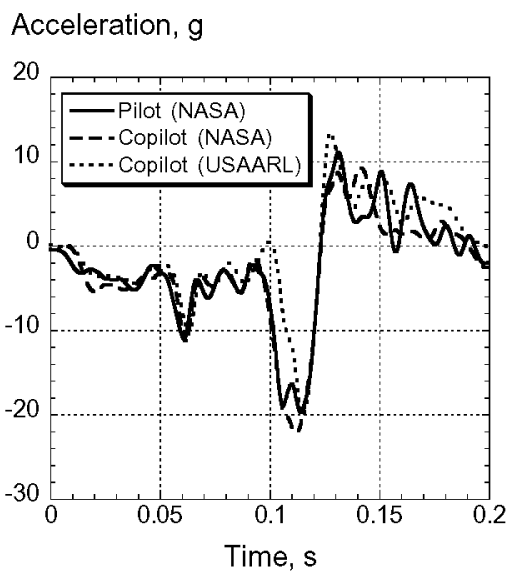

(a) Forward acceleration responses.

Acceleration, $\mathrm{g}$

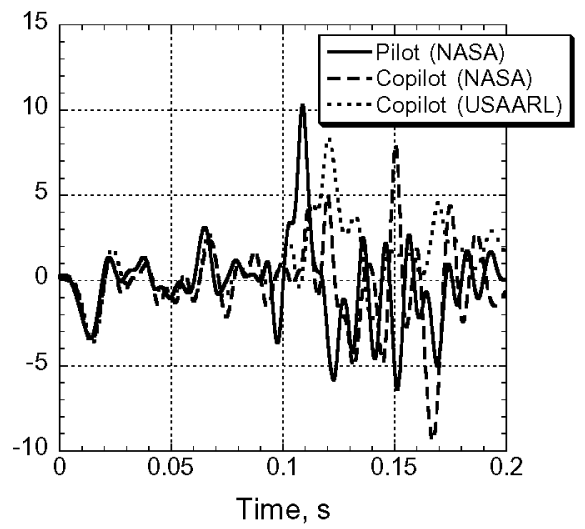

(b) Side acceleration responses.

Acceleration, g

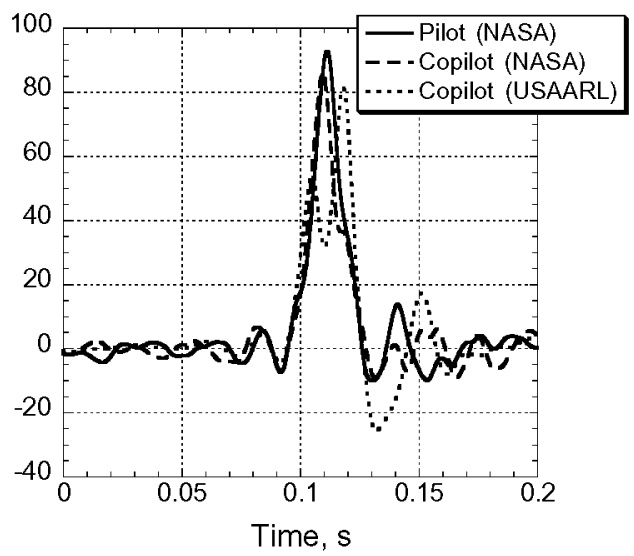

(c) Vertical acceleration responses.

Figure 13. Filtered acceleration responses of the pilot and copilot seat floor as measured by the NASA and USAARL data acquisition systems. 


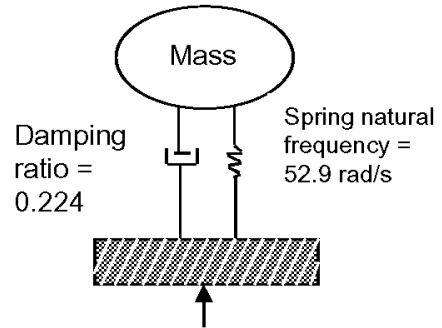

$a(t)$

Figure 14. Schematic of the DRI injury model.

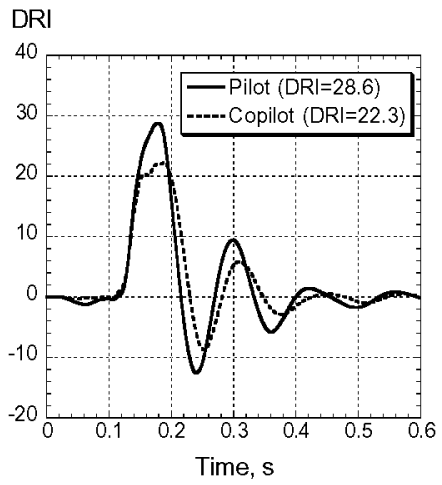

(a) Pilot and copilot.

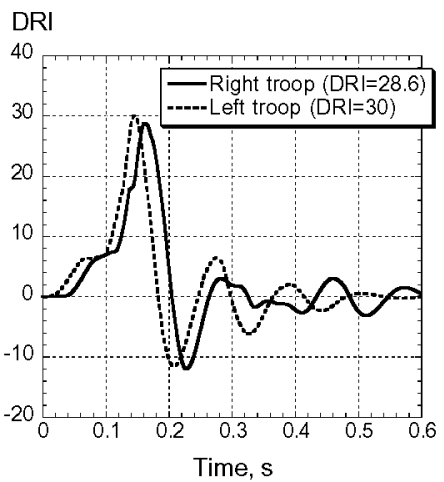

(b) Right and left troop.

Figure 15. Continuous DRI responses of the four dummy occupants.

Acceleration, $g$

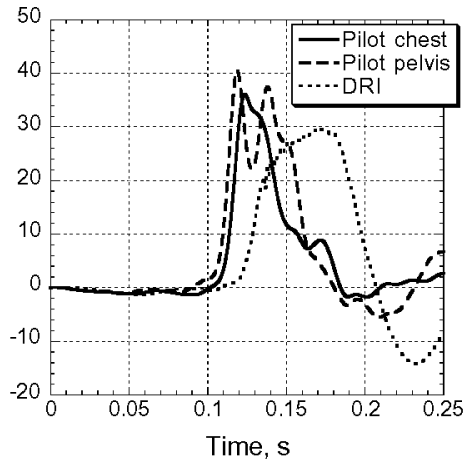

(a) Pilot chest and pelvis data with DRI.

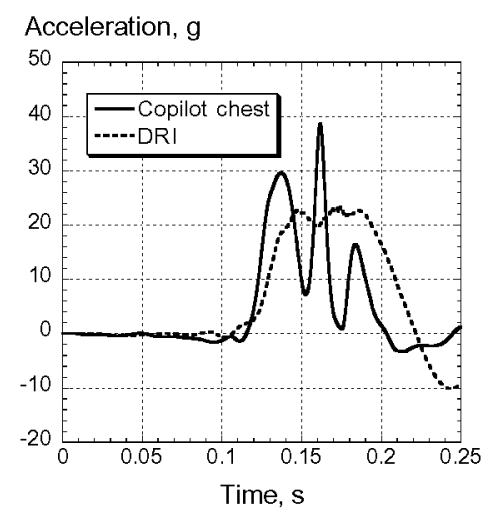

(b) Copilot chest data with DRI.

Acceleration, $\mathrm{g}$

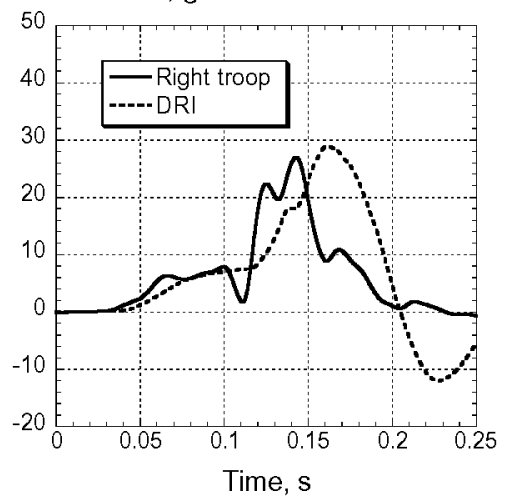

(c) Right troop chest data with DRI.

Acceleration, $\mathrm{g}$

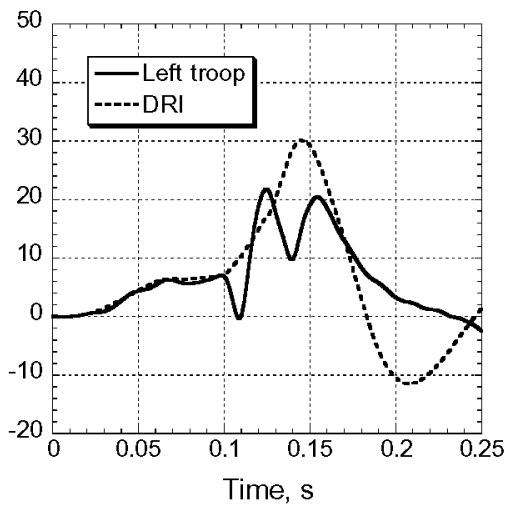

(d) Left troop chest data with DRI.

Figure 16. Comparison of occupant responses with the continuous DRI.

In general, the continuous DRI model under predicts the peak accelerations of the pilot and copilot responses, and over predicts the peak accelerations of the troop responses. Also, the time of occurrence of the peak acceleration is delayed for the DRI model in comparison with the test data. The continuous DRI data 
for the troop occupants must be viewed with caution, since the cloth seat pan was torn during the test, allowing the buttocks of the troop dummies to displace through the seat frame. Consequently, the vertical response of the seat frame is not likely to be a good indicator of occupant response or injury potential for the troop dummies.

The one-dimensional DRI model has obvious limitations for application to impact scenarios involving multi-directional acceleration components. A more comprehensive method was developed to account for acceleration components in the three orthogonal axes on the human occupant [16]. A FORTRAN program DYNRESP [17], obtained from NASA Johnson Space Center, was used to calculate the dynamic response and injury risk assessment of a seated occupant by analyzing the measured $x$, $y$, and $z$ linear accelerations of the seat. These directions are defined in Figure 17. The dynamic response of the occupant is modeled by a mass, spring, and damper system attached to the seat. Each orthogonal axis is modeled with a different spring-damper representation. The general risk of injury is determined based on the combined dynamic responses of the three axes and the defined limits in these directions using Equation 1:

$$
\beta=\left[\left(\frac{\mathrm{DRX}}{\mathrm{DRX}_{\mathrm{L}}}\right)^{2}+\left(\frac{\mathrm{DRY}}{\mathrm{DRY}_{\mathrm{L}}}\right)^{2}+\left(\frac{\mathrm{DRZ}}{\mathrm{DRZ}_{\mathrm{L}}}\right)^{2}\right]^{1 / 2}
$$

where DRX, DRY, and DRZ are the dynamic responses for the $x_{-}, y-$, and $z$-axes; $D R X_{L}$, $D R Y_{L}$, and $D R Z_{L}$ are the limit values defined for low, moderate, and high risk, and $\beta$ is the injuryrisk criterion. Different dynamic response limit values, listed in Table 1, are used for low, moderate, and high risk [16]. Risk levels for injury are considered satisfactory if $\beta$ is less than 1 .

This model was applied by inputing the forward $(x)$ and vertical $(z)$ components of acceleration obtained from the pilot and copilot seats into the dynamic response model described by Equation 1. No side component of acceleration was input since it was not measured in the test. Data from other locations indicate that the side accelerations were minimal and, therefore, the omission of this component should not significantly affect these computations. The results of this injury risk assessment are shown in Figure 18. For the pilot, all three of the risk assessment curves exceed the threshold value of 1.0 , indicating a high risk of injury. For the copilot, the high-risk curve is close to 1.0, but does not exceed the threshold. Thus, the results indicate a moderate risk of injury for the copilot.

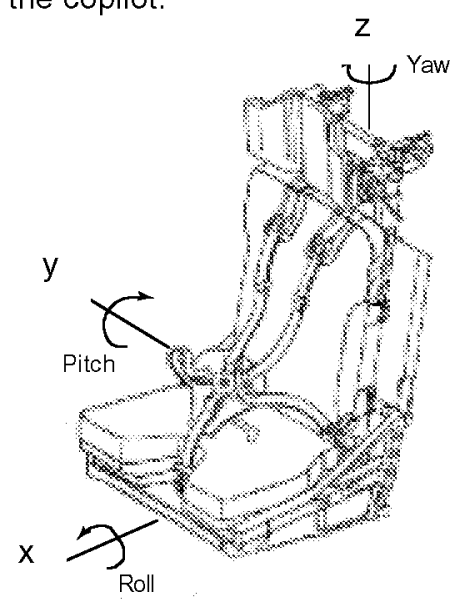

Figure 17. Axis system used to calculate the combined DRI response.

Table 1. Dynamic Response Limit Values for Low, Moderate, and High Risk

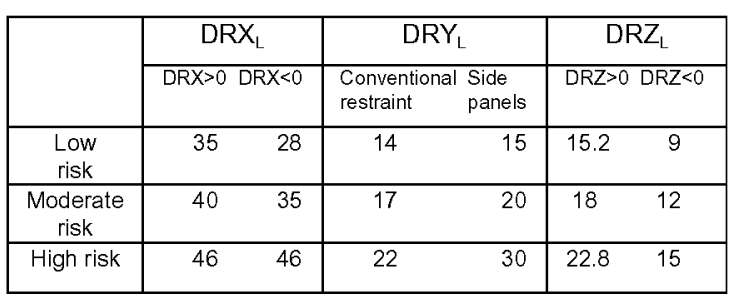

Spinal Force

A second injury assessment criteria, defined in FAR Part 27.562 (c), is that spinal load should not exceed $1,500 \mathrm{lbs}$ [12]. Both the pilot and copilot dummies were instrumented with lumbar load cells to measure force along the spine. A plot of lumbar load versus time is shown in Figure 19 for the pilot and copilot dummies. Initially the load is tensile perhaps from the forward motion of the dummy as the helicopter slows down horizontally. The maximum compressive loads measured for the pilot and copilot dummies are 1,912 and 1,921 lbs., respectively. These loads occur during fuselage floor impact and about .005 seconds after the peak pelvis vertical acceleration. They exceed the $1,500-\mathrm{lb}$. threshold for spinal injury which is the maximum load for civil seat certification [12]. 


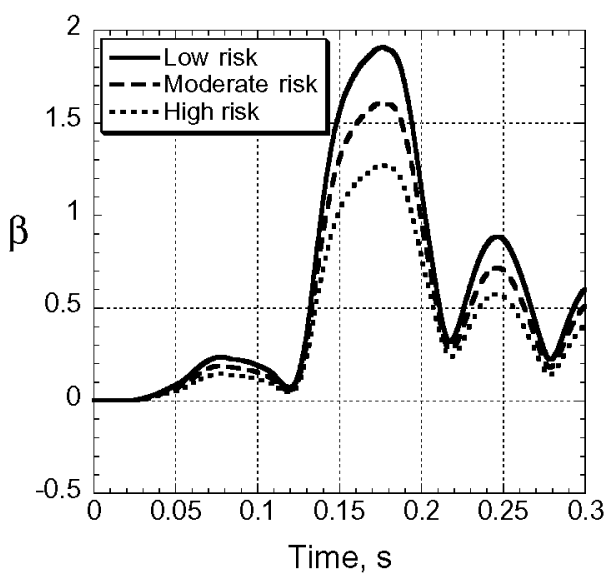

(a) Pilot.

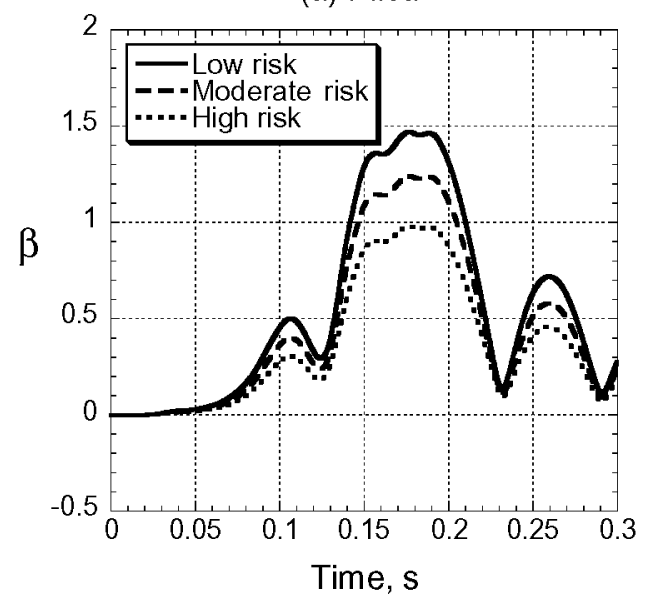

(b) Copilot.

Figure 18. Injury risk assessment for the pilot and copilot dummies.

Lumbar load, lbs.

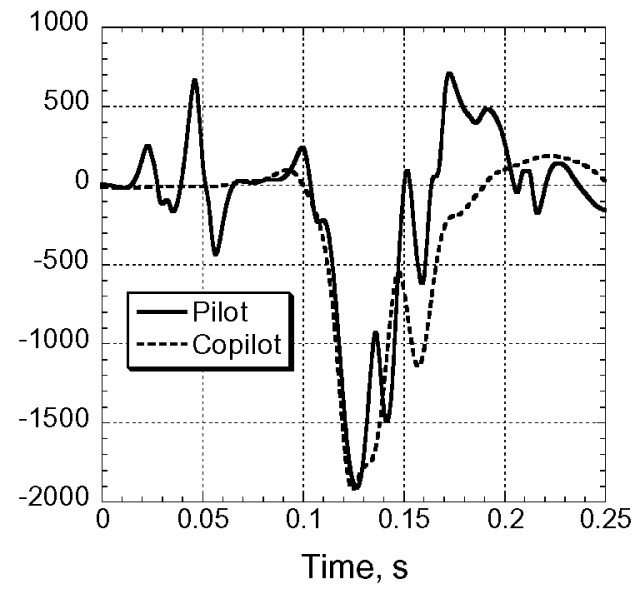

Figure 19. Filtered pilot and copilot vertical lumbar load responses.

\section{Head Injury Criteria (HIC)}

The Federal Motor Vehicle Safety Standard 208 (FMVSS 208 [18]) includes a head impact tolerance specification called the Head Injury Criteria (HIC) [19]. The HIC was originally developed as a modification of the Wayne State University Tolerance Curve [20] and is calculated by the following equation:

$$
\mathrm{HIC}=\left\{\left(\mathrm{t}_{2}-\mathrm{t}_{1}\right)\left[\frac{1}{\mathrm{t}_{2}-\mathrm{t}_{1}} \int_{\mathrm{t}_{1}}^{\mathrm{t}_{2}} \mathrm{a}(\mathrm{t}) \mathrm{dt}\right]^{2.5}\right\}
$$

where $t_{1}$ is the initial time of integration, $t_{2}$ is the final time of integration, $a(t)$ is the resultant acceleration in g's measured at the center-ofgravity of the head. The FMVSS 208 establishes a maximum value of 1000 for the HIC, which is associated with a 16 percent risk of serious brain injury. It also specifies that the time interval, i.e. $t_{2}$ minus $t_{1}$, used in the integration should not exceed .036 seconds. Limitations in using the HIC have been documented in the literature [21], including a study that found that the critical time duration used in the HIC calculation should be equal to or less than .015 seconds [19]. For this evaluation, both time intervals are used in the HIC calculation.

The resultant head acceleration response was calculated for the copilot dummy occupant, as plotted in Figure 20. For the pilot, only the vertical and side components of acceleration were available, since the forward acceleration channel was lost after 0.15 seconds. Consequently, no HIC calculation was attempted for the pilot. As shown in Figure 20, the copilot experiences a peak acceleration of almost $500-\mathrm{g}$ at 0.188 seconds. The duration of this acceleration spike is approximately .003 seconds. The data shown in Figure 20 were used to calculate HIC values for time intervals of 0.036 and 0.015 seconds. The initial time, $t_{1}$, used in the $\mathrm{HIC}$ calculations was varied systematically from the beginning of the pulse to determine the maximum value of $\mathrm{HIC}$.

The results of the HIC analysis, shown in Table 2, indicate that the copilot experienced a head impact during the crash test. The copilot $\mathrm{HIC}$ values were 713 and 1185 for time intervals of 0.036 - and 0.015 -seconds, respectively. These results also confirm the need to evaluate $\mathrm{HIC}$ for different time intervals. In this case, the 
higher value of HIC (greater than 1000) was found using the shorter ( 0.015 second) time interval.

Resultant acceleration, $\mathrm{g}$

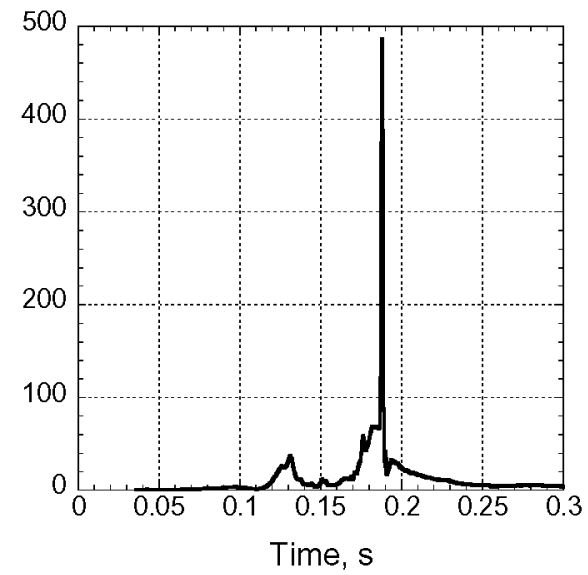

Figure 20. Resultant acceleration responses of the pilot and copilot head.

\section{Whole-Body Acceleration Tolerance}

The crew and troop occupant acceleration responses are compared with the wholebody acceleration tolerance curve established by Eiband [22]. The Eiband acceleration tolerance levels were determined from sled impact tests on human volunteers, pigs, and chimpanzees that were conducted for a single input acceleration pulse in the lateral, longitudinal, and vertical directions. Since the ACAP helicopter crash test was performed under combined velocity conditions, the results of this comparison must be viewed with caution. In addition, the Eiband curve was determined for a trapezoidalshaped input acceleration pulse consisting of three phases: a ramp up phase to a uniform acceleration phase followed by a ramp down phase, as illustrated in Figure 21. The duration and magnitude of the uniform phase of the acceleration pulse, shown as the cross-hatched area in Figure 21, is then plotted on the Eiband curve. However, the vertical acceleration responses of the crew and troop occupants are sinusoidal in shape, not trapezoidal, as indicated in Figure 21. Consequently, the peak acceleration and the pulse duration of the sinusoidalshaped acceleration response are plotted on the Eiband curve. This approach was used for the pilot, copilot, and troop results and it provides a conservative estimate of injury prediction, i.e. it likely over predicts the severity of injury.
Table 2. Summary of head injury assessment.

\begin{tabular}{|c|c|}
\hline & Copilot \\
\hline Peak resultant head accel., g & 486.7 \\
\hline Time of peak acceleration, s & 0.188 \\
\hline HIC for time duration of $.036 \mathrm{~s}$ & 713 \\
\hline HIC for time duration of $.015 \mathrm{~s}$ & 1185 \\
\hline
\end{tabular}

The magnitude and duration of the pilot chest and pelvis vertical acceleration responses are plotted on the Eiband curve in Figure 22. These data fall on the border between areas of moderate and severe injury. Likewise the magnitude and duration of the copilot chest (torso sternum) vertical acceleration response are plotted on the Eiband curve in Figure 23. For the copilot, the results fall slightly more into the area for moderate injury. Finally, the magnitude and duration of the vertical chest acceleration responses of the right and left troop dummies are plotted on the Eiband curve in Figure 24. The troop data also fall into the area for moderate injury.

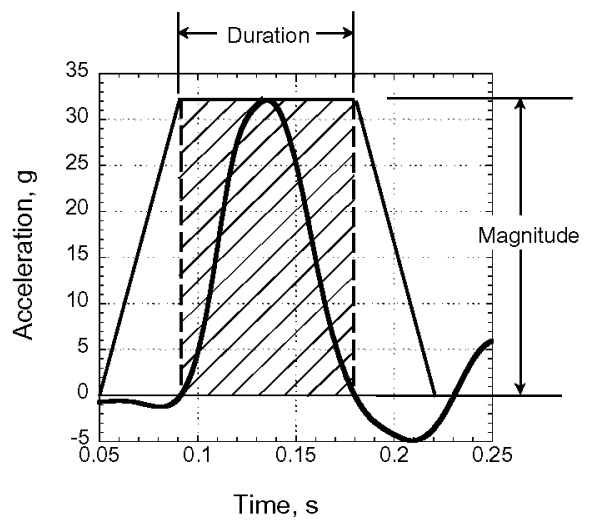

Figure 21. Vertical acceleration of the pilot pelvis fitted to the Eiband trapezoidal pulse.

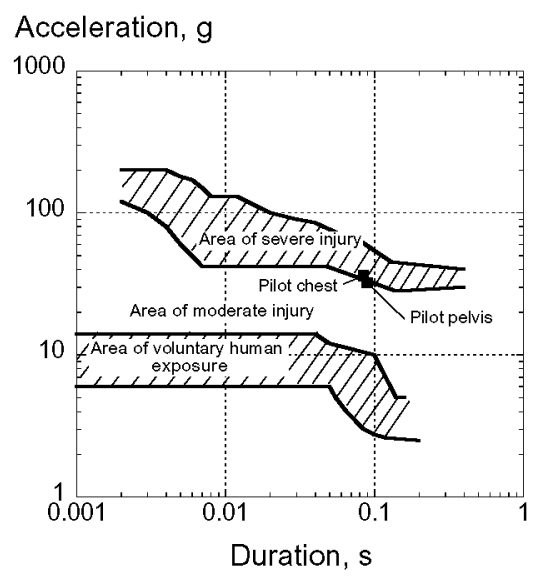

Figure 22. Pilot chest and pelvis vertical acceleration data plotted on the Eiband curve. 
Acceleration, $g$

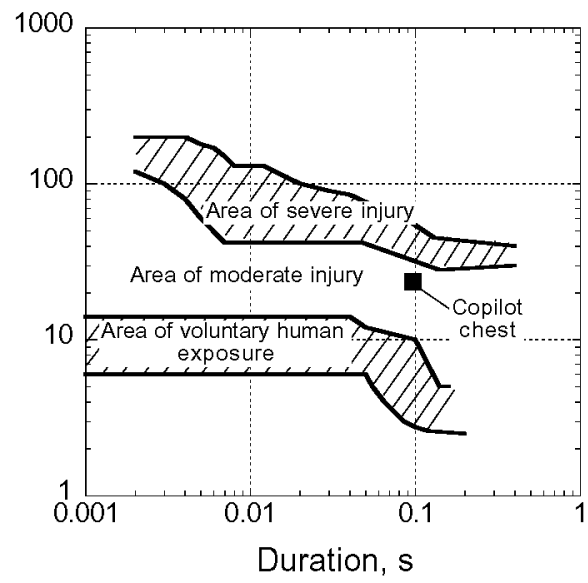

Figure 23. Copilot chest vertical acceleration response plotted on the Eiband curve.

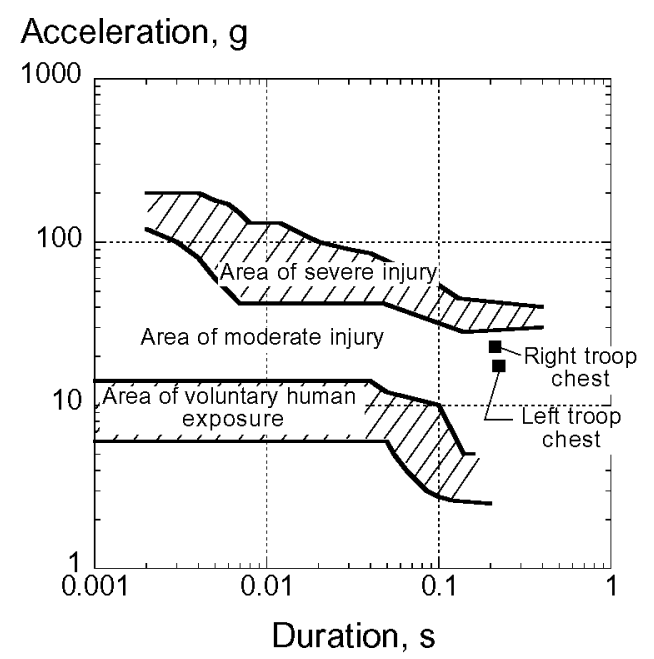

Figure 24. Vertical chest acceleration data of the troop dummies plotted on the Eiband curve.

\section{Injury Assessment Reference Values for Re- strained Occupants}

Injury Assessment Reference Values (IARVs) are provided in Reference 23 for restrained Hybrid III dummy occupants. Injury guidelines are specified for head and neck forces and moments; head and chest accelerations; neck force and moment; and femur loads. These injury guidelines are listed in Table 3 along with corresponding measurements from the modified Hybrid III anthropomorphic dummy representing the copilot, where applicable. The results shown in Table 3 are for a mid-size (50th percentile) male occupant. The IARVs have been suggested as guidelines for assessing in- jury potentials associated with measurements made with Hybrid III-type adult dummies. The IARVs refer to a human response level below which a specified injury is considered unlikely to occur for the given size individual. The data for the copilot dummy are less than the IARVs listed in Table 3 with the exception of head/neck tensile force, neck compression force, and HIC. These results indicate a high probability of head and neck injury as a result of head strike.

Table 3. Comparison of copilot data with Injury Assessment Reference Values (IARVs).

\begin{tabular}{lccc} 
Units & $\begin{array}{c}\text { Mid-size } \\
\text { male } \\
\text { IARV }\end{array}$ & $\begin{array}{c}\text { Copilot } \\
\text { dummy } \\
\text { data }\end{array}$ \\
\hline Head/neck & in-lb. & 1684 & 518.1 \\
$\quad$ Flex moment & in-lb. & 505 & 215.2 \\
Extension moment & lb. & 247 & 245.9 \\
Shear (fore/aft) & lb. & 247 & 617.5 \\
Tension & lb. & 247 & 217.5 \\
$\quad$ Compression & g & 60 & 47.7 \\
Chest acceleration & & & \\
(fore/aft) & HIC & 1000 & 1185 \\
Head (t t $_{2}$ ) $\leq 15$ ms & & & \\
Neck & in-lb. & 1684 & 1201.8 \\
Neck moment & lb. & 247 & 444.4 \\
Neck compression & & &
\end{tabular}

\section{Discussion of Results}

The crew seat pan accelerations, shown in Figures 4 and 11(a), are higher than desired and may be attributed to the fact that the original energy absorbing nose gear that was designed for the Sikorsky ACAP helicopter was not available for this test. Instead, a standard noncrashworthy commercial nose gear that was retrofitted to provide a nominal level of energy absorption was installed on the helicopter. The retrofitted nose gear did not provide sufficient energy attenuation and failed early during the test. If the original crashworthy nose gear had been available, the combination of nose gear crushing plus seat stroke might have lowered these acceleration levels.

The chest acceleration comparisons between the crew and troop dummy occupants shown in Figure 8 appear to be counter-intuitive. These plots indicate that the troop occupants experienced lower forward and vertical chest acceleration responses than did the crew dummies, in spite of the fact that the crew seats exhibited 9- and 14.5-inches of stroking and the troop seats had minimal stroking. The explanation for this behavior is that the troop dummies 
benefited from the fact that they were located in close proximity to the center-of-gravity of the helicopter and were placed almost directly above the main landing gear.

To illustrate this point, the raw data obtained from accelerometers located on the floor near the pilot and right troop, and near the copilot and left troop were integrated to obtain the vertical velocity responses shown in Figure 25. The initial velocity was determined for each location as the sum of the initial vertical velocity of the center-of-gravity plus the rotational component which is the pitch angular velocity times the distance from the accelerometer location to the center-of-gravity. As shown in Figure 25, the magnitude of the velocity response of the pilot and copilot floor increases slightly for the first 0.1 seconds of the pulse, whereas the magnitude of the velocity response of the right and left troop floor is decreasing during the same time period. At the time of fuselage contact with the ground at 0.098 seconds, the velocity at the pilot and copilot floor is approximately $-460 \mathrm{in} / \mathrm{s}$. The corresponding velocity of the right and left troop floor is $-300 \mathrm{in} / \mathrm{s}$ at the same time. Thus, the right and left troop dummies benefited from the energy attenuation achieved from crushing of the aluminum honeycomb stage of the main landing gear. In contrast, the original energy absorbing nose gear was missing from the ACAP helicopter and a modified civil helicopter nose gear was retrofitted to the airframe. The replacement gear was not designed to provide a high-level of energy absorption and failed early upon impact after providing 9 inches of stroke [11].

It is interesting to note the differences in the shape, magnitude, and duration of the pilot and copilot chest acceleration responses in both the vertical and forward directions, shown in Figures 8(a) and 9(a). In general, the copilot data exhibits more oscillations than the pilot data. In contrast, the vertical and forward acceleration responses of the right and left troop, shown in Figures $8(b)$ and $9(b)$, have the same overall shape, duration, and magnitude. The variations in crew occupant responses cannot be attributed to differences in the seat pan or floor-level acceleration pulses, which are shown in Figures 11 and 13, respectively. Therefore, the varying responses must be attributed to the differences in the Hybrid II (pilot) and the modified Hybrid III (copilot) dummies.

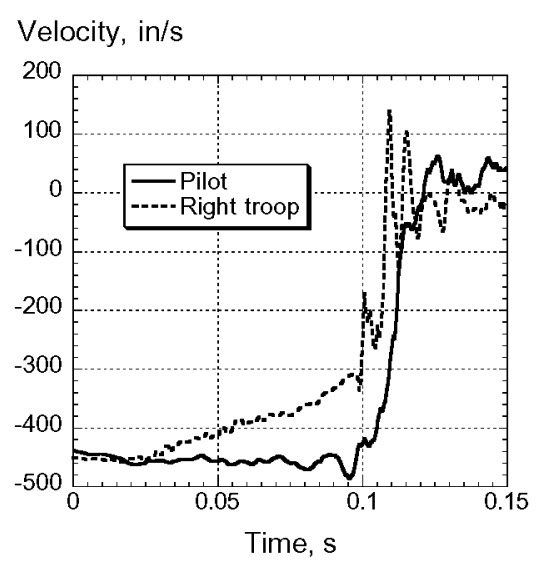

(a) Pilot and right troop floor.

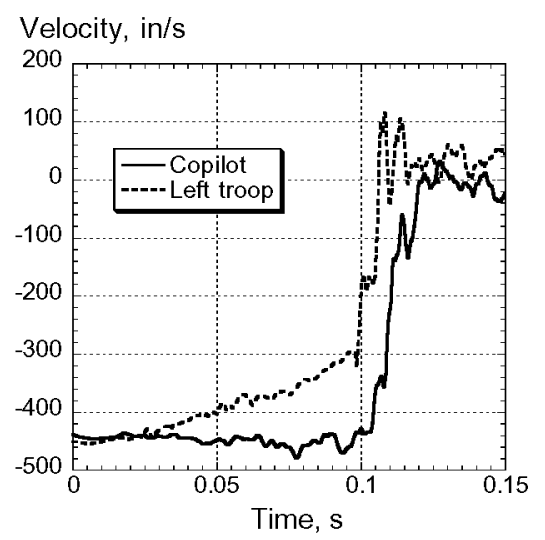

(b) Copilot and left troop floor.

Figure 25. Vertical velocity responses.

It is evident from the copilot head and T1 thoracic acceleration responses, plotted in Figures 6 and 7 respectively, and the head and neck forces listed in Table 3 that the copilot dummy experienced a head strike during the crash test. As mentioned previously, a small piece of cloth matching the fabric in the copilot's flight suit was found on the right side of the dummy's forehead that appeared to originate from the dummy's knee. The actual head strike with the dummy's knee could be seen in the high-speed film, which showed that the copilot's head and upper torso experienced a large downward translation and forward rotation during the test. The copilot displayed more forward motion of its upper torso and head than did the pilot dummy. The forward pitching of the copilot seat back and the added weight of the helmet contributed to the excessive forward motion of the copilot. 
The HIC values determined from the resultant head acceleration of the copilot ranged from 713 to 1185 depending on the time interval used in the calculation. For the mid-size Hybrid III dummy, HIC values greater than 1000 are indicative of a 16 percent risk of serious brain injury. The maximum one-dimensional DRI value of 22.3 for the copilot was the lowest of any of the four dummy occupants, yet still indicates a $40 \%$ risk of spinal injury. The spinal force measured for the copilot was 1,921 lbs, which exceeded the 1,500-lb. threshold. In addition, the magnitude and duration of the copilot chest acceleration response falls into the region for moderate injury on the Eiband whole-body acceleration tolerance curve.

Without the forward component of head acceleration, it was not possible to perform a HIC assessment for the pilot occupant. However, the other injury criteria indicate that the pilot experienced moderate to severe injury. The maximum DRI for the pilot was 28.6, indicating a greater than $50 \%$ risk of spinal injury. The risk assessment for the pilot using the combined dynamic response model shown in Equation 1 indicated that each of the low-, moderate-, and high-risk curves exceeded the threshold value. The maximum lumbar load measured for the pilot was 1,912 lbs, exceeding the 1,500-lb. limit for spinal injury. Finally, the magnitude and duration of the pilot chest and pelvic vertical acceleration responses fell on the border between moderate and severe injury on the Eiband whole-body acceleration tolerance curve.

Less detailed occupant response information was available for the troop dummies as compared to the crew dummies since they were less heavily instrumented. The maximum DRI values for these occupants ranged from 28.6 to 30 , indicating a greater than $50 \%$ risk for spinal injury. However, these values must be viewed with caution, since the cloth seat pans in the troop seats failed during the test allowing the buttocks of the dummy occupants to displace through the seat frame. Consequently, the vertical response of the seat frame is not likely to be a good indicator of occupant response or injury potential for the troop dummies. The magnitude and duration of the vertical chest acceleration responses of the left and right troop dummies fell into the area of moderate risk on the Eiband whole-body acceleration tolerance curve.
As mentioned previously, several different criteria were applied to each occupant to determine the risk of injury for this crash test and consistent results were obtained. The overall assessment of occupant injury indicates that the ACAP helicopter crash test resulted in a moderate to high level of risk for injury. Although some injuries would likely have occurred in this crash, the probability of a fatality is considered small.

\section{Concluding Remarks}

A full-scale crash test of the Sikorsky ACAP flight test helicopter was performed at the Impact Dynamics Research Facility at NASA Langley Research Center in June 1999. The purpose of the test was to generate experimental data for correlation with a nonlinear, explicit transient dynamic crash simulation developed using the MSC.Dytran finite element code. For the test, the helicopter was outfitted with two crew and two troop seats, and four anthropomorphic test dummies. While the results of the impact test and crash simulation have been documented fairly extensively in the literature, the objective of this paper is to present the detailed occupant response data obtained from the crash test and to correlate the results with injury prediction models. These injury models include the Dynamic Response Index (DRI), the Head Injury Criteria (HIC), the spinal load requirement defined in FAR Part 27.562(c), and a comparison of the duration and magnitude of the occupant vertical acceleration responses with the Eiband whole-body acceleration tolerance curve.

The pilot was a 50 th percentile Hybrid II male dummy that was placed in a used commercial military-qualified helicopter seat provided by the US Army Aeromedical Research Laboratory (USAARL). This seat contained two invertube energy absorbers. New MA-16 inertia locking reels were used with lap and shoulder belts to restrain the dummy occupant during the test. USAARL also supplied a 50th percentile modified Hybrid III male dummy with a selfcontained data acquisition system (DAS) for the left front crew (copilot). The copilot dummy was secured in a used commercial military-qualified helicopter seat of a different design than the pilot seat. This seat contained six "torshock" energy absorbers. Likewise, an MA-16 inertia locking reel was used in conjunction with the restraint system to limit the displacement of the dummy occupant during the test. Two 50th percentile 
Hybrid II male dummies were used for the right and left troop occupants. These dummies were seated in ceiling-suspended troop seats with wire-bender energy absorbers that were mounted in the rear cabin area. New wirebender energy absorbers were installed in the troop seats; however, these seats were used and the seating material was in poor condition.

The head and chest acceleration responses of the copilot indicate a strong likelihood of head strike. In fact, the HIC values for the copilot ranged from 713 to 1185 , depending on the time interval used in the calculation. $A$ $\mathrm{HIC}$ of 1000 is associated with a 16 percent risk of serious brain injury. The maximum onedimensional DRI value of 22.3 for the copilot was the lowest of any of the four dummy occupants, yet still indicates a $40 \%$ risk of spinal injury. The spinal force measured for the copilot was 1,921 lbs, which exceeded the 1,500-lb. threshold. In addition, the magnitude and duration of the copilot chest acceleration response falls into the region for moderate injury on the Eiband whole-body acceleration tolerance curve. The maximum DRI for the pilot was 28.6 and the lumbar load was 1,912-lb., both of which are strong indicators of spinal injury. Less detailed occupant response information was available for the troop dummies as compared to the crew dummies since they were less heavily instrumented. However, the magnitude and duration of the vertical chest acceleration responses of the left and right troop dummies fell into the area of moderate risk on the Eiband whole-body acceleration tolerance curve.

Finally, several different criteria were applied to each occupant to determine the risk of injury for this crash test and consistent results were obtained. The overall assessment of occupant injury indicates that the ACAP helicopter crash test resulted in a moderate to high level of risk for injury. Although some injuries would likely have occurred in this crash, the probability of a fatality is considered small.

\section{Acknowledgements}

The authors wish to acknowledge the support of the US Army Aeromedical Research Laboratory (USAARL) in providing the modified Hybrid III anthropomorphic dummy with selfcontained data acquisition system and seats for use in the ACAP helicopter full-scale crash test.
In addition, we would like to acknowledge $H$. Koch and Sons for providing new MA-16 inertia locking reels and restraint systems for the test.

\section{References}

1. Vaughan, Victor L., Jr. and Alfaro-Bou, Emilio, "Impact Dynamics Research Facility for FullScale Aircraft Crash Testing," NASA TN D-8179, April 1976.

2. Cronkhite, J. D., and Mazza, L. T., "Bell ACAP Full-Scale Aircraft Crash Test and KRASH Correlation," Proceedings of the 44th Annual Forum and Technology Display of the American Helicopter Society, Washington D.C., June 16-18, 1988.

3. Perschbacher, J.P., Clarke, C., Furnes, K., and Carnell, B., "Advanced Composite Airframe Program (ACAP) Militarization Test and Evaluation (MT\&E) Volume V- Airframe Drop Test," USAATCOM TR 88-D-22E, March 1996.

4. Jones, L. E., "Overview of the NASA's Systems Approach to Crashworthiness Program," Proceedings of the American Helicopter Society 58th Annual Forum, Montreal, Canada, June 1113, 2002.

5. MSC.Dytran User's Guide, Version 2002, MSC.Software Corporation, Santa Ana, CA, November 2001.

6. Fasanella, E.L., Jackson, K.E. and Lyle, K.H., "Finite Element Simulation of a Full-Scale Crash Test of a Composite Helicopter," Proceedings of the American Helicopter Society $56^{\text {th }}$ Annual Forum, Virginia Beach, Virginia, May 2-4, 2000.

7. Lyle, K. H., Jackson, K.E., and Fasanella, E. L., "Development of an ACAP Helicopter Impact Model," Journal of the American Helicopter Society, Vol. 45, No. 2, April 2000, pp. 137-142.

8. Fasanella, E. L., Boitnott, R. L., Lyle, K. H., and Jackson, K. E., "Full-Scale Crash Test and Simulation of a Composite Helicopter," International Journal of Crashworthiness, Vol. 6, No. 4, November 2001, pp. 485-498.

9. K. H. Lyle, K. E. Jackson, and E. L. Fasanella, "Simulation of Aircraft Landing Gears with a Nonlinear Transient Dynamic Finite Element 
Code," Journal of Aircraft, Vol. 39, No. 1, January-February, 2002.

10. Boitnott, R. L., Jackson, K. E., Fasanella, E. L., and Kellas, S.: "Full-Scale Crash Test of the Sikorsky Advanced Composite Airframe Program Helicopter," Proceedings of the American Helicopter Society Forum 56, Virginia Beach, VA, May 2-4, 2000.

11. Boitnott, R. L., Jones, L. E., "NASA Langley Research Center's Impact Dynamics Research Facility Full-Scale Crash Test Procedures," Proceedings of the 3rd KRASH Users Seminar, Arizona State University, Tempe, AZ, January 810, 2001.

12. Code of Federal Regulations, Federal Aviation Regulations for Aviation Maintenance Technicians FAR AMT, Part 27 Airworthiness Standard: Normal Category Rotorcraft, 27.562 Emergency Landing Dynamics.

13. Stech, E. L. and Payne, P. R., "Dynamic Models of the Human Body," AAMRL-TR-66157, Aerospace Medical Research Laboratory, Wright-Patterson Air Force Base, Ohio, 1969.

14. Brinkley, J. W. and Shaffer, J. T., "Dynamic Simulation Techniques for the Design of Escape Systems: Current Applications and Future Air Force Requirements," Aerospace Medical Research Laboratory; AMRL Technical Report 71292, Wright-Patterson Air Force Base, Ohio, December 1971, AD 740439.

15. Coltman, J. W., Van Ingen, C., Johnson, N. B., and Zimmerman, R. E., "Crash Survival Design Guide, Volume II - Aircraft Design Crash Impact Conditions and Human Tolerance," USAAVSCOM TR 89-D-22B, December 1989.

16. Brinkley, J. W. and Mosher, S. E., "Development of Acceleration Exposure Limits to Advanced Escape Systems," Implications of $A d-$ vanced Technologies for Air and Spacecraft Escape, AGARD-CP-472, April 24-28, 1989.

17. Mosher, S. E., "DYNRESP Six Degree-ofFreedom Model for Injury-Risk Evaluation User's Manual," NASA Johnson Space Center, April 29, 1993.

18. Federal Motor Vehicle Safety Standard No. 208, Occupant Crash Protection, Code of Fed- eral Regulations, Title 49, Part 571.208, U. S. Government Printing Office, Washington D. C., 1987.

19. Anon., "Human Tolerance to Impact Conditions As Related to Motor Vehicle Design SAEJ885," APR 80, SAEJ885, Society of Automotive Engineers, Inc., Warrendale, PA, April 1980.

20. Gadd, C. W., "Use of a Weighted-Impulse Criterion for Estimating Injury Hazard, "Proceedings of the Tenth Stapp Car Crash Conference, Society of Automotive Engineers, New York, 1966.

21. Nusholtz, G. S., et al., "Critical Limitations on Significant Factors in Head Injury Research," Proceedings of the 13th Stapp Car Crash Conference, Society of Automotive Engineers, Inc., Warrendale, PA, October, 1986.

22. Eiband, A. M., "Human Tolerance to Rapidly Applied Accelerations: A Summary of the Literature," NASA Memorandum 5-19-59E, National Aeronautics and Space Administration, Washington D.C., June 1959.

23. Mertz, H. J., "Injury assessment values used to evaluate Hybrid III response measurements," NIHTSA Docket 74-14, Notice 32, Enclosure 2 of Attachment I of Part III of General Motors Submission USG 2284. March 22, 1984. 


\begin{tabular}{|c|c|c|c|c|}
\hline \multicolumn{3}{|c|}{ REPORT DOCUMENTATION PAGE } & \multicolumn{2}{|r|}{$\begin{array}{l}\text { Form Approved } \\
\text { OMB No. 0704-0188 }\end{array}$} \\
\hline \multicolumn{5}{|c|}{$\begin{array}{l}\text { Public reporting burden for this collection of information is estimated to average } 1 \text { hour per response, including the time for reviewing instructions, searching existing data sources, } \\
\text { gathering and maintaining the data needed, and completing and reviewing the collection of information. Send comments regarding this burden estimate or any other aspect of this } \\
\text { collection of information, including suggestions for reducing this burden, to Washington Headquarters services, Directorate for Informatiton Operations and Reports, } 1215 \text { J Jefferson } \\
\text { Davis Highway, Sulte 1204, Arlington, VA22202-4302, and to the office of Management and Budget, Paperwork Reduction Project (0704-0188), Washington, DC 20503. }\end{array}$} \\
\hline 1. AGENCY USE ONLY (Leave blank) & \begin{tabular}{|l|} 
2. REPORT DATE \\
June 2002
\end{tabular} & \multicolumn{3}{|c|}{$\begin{array}{l}\text { 3. REPORT TYPE AND DATES COVERED } \\
\text { Technical Memorandum }\end{array}$} \\
\hline \multicolumn{3}{|c|}{$\begin{array}{l}\text { 4. TITLE AND SUBTITLE } \\
\text { Occupant Responses in a Full-Scale Test of the Sikorsky ACAP Helicopter }\end{array}$} & \multirow{2}{*}{\multicolumn{2}{|c|}{$\begin{array}{l}\text { 5. FUNDING NUMBERS } \\
\text { WU 728-50-10-01 }\end{array}$}} \\
\hline \multicolumn{3}{|c|}{$\begin{array}{ll}\text { 6. AUTHOR(S) } & \\
\text { Karen E. Jackson } & \text { Joseph McEntire } \\
\text { Edwin L. Fasanella } & \text { Alan Lewis } \\
\text { Richard L. Boitnott } & \end{array}$} & & \\
\hline \multicolumn{3}{|c|}{ 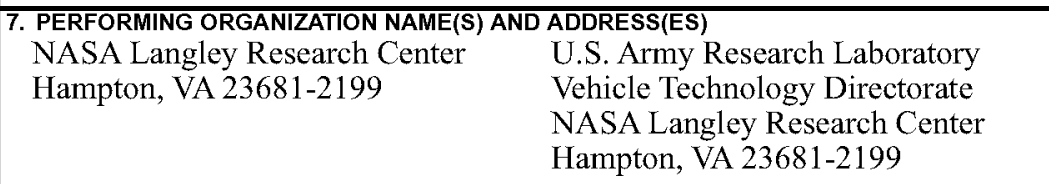 } & \multicolumn{2}{|c|}{$\begin{array}{l}\text { 8. PERFORMING ORGANIZATION } \\
\text { REPORT NUMBER } \\
\text { L-18189 }\end{array}$} \\
\hline \multicolumn{2}{|c|}{$\begin{array}{l}\text { 9. SPONSORING/MONITORING AGENCY NAME(S) AND } \\
\text { National Aeronautics and Space Administra } \\
\text { Washington, DC 20546-0001 } \\
\text { and } \\
\text { U.S. Army Research Laboratory } \\
\text { Adelphi, MD 20783-1145 }\end{array}$} & & \multicolumn{2}{|c|}{$\begin{array}{l}\text { 10. SPONSORING/MONITORING } \\
\text { AGENCY REPORT NUMBER } \\
\text { NASA/TM -2002-211733 } \\
\text { ARL-TR-2735 }\end{array}$} \\
\hline \multicolumn{5}{|c|}{$\begin{array}{l}\text { 11. SUPPLEMENTARY NOTES } \\
\text { Presented at the AHS International - The Vertical Flight Society's 58th Annual Forum and Technology Display, } \\
\text { June } 11-13,2002 \text {, Montreal, Canada. }\end{array}$} \\
\hline \multicolumn{3}{|c|}{ 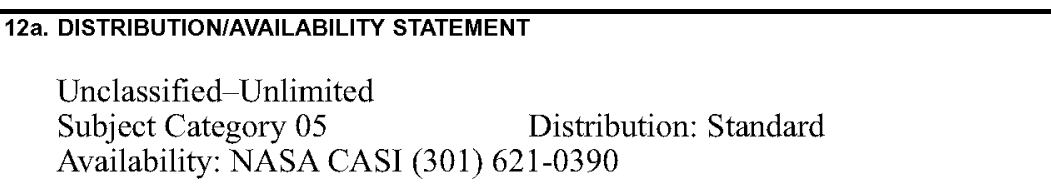 } & \multicolumn{2}{|c|}{ 12b. DISTRIBUTION CODE } \\
\hline \multicolumn{5}{|c|}{$\begin{array}{l}\text { A full-scale crash test of the Sikorsky Advanced Composite Airframe Program (ACAP) helicopter was performed } \\
\text { in } 1999 \text { to generate experimental data for correlation with a crash simulation developed using an explicit nonlinear, } \\
\text { transient dynamic finite element code. The airframe was the residual flight test hardware from the ACAP program. } \\
\text { For the test, the aircraft was outfitted with two crew and two troop seats, and four anthropomorphic test dummies. } \\
\text { While the results of the impact test and crash simulation have been documented fairly extensively in the literature, } \\
\text { the focus of this paper is to present the detailed occupant response data obtained from the crash test and to correlate } \\
\text { the results with injury prediction models. These injury models include the Dynamic Response Index (DRI), the } \\
\text { Head Injury Criteria (HIC), the spinal load requirement defined in FAR Part } 27.562 \text { (c), and a comparison of the } \\
\text { duration and magnitude of the occupant vertical acceleration responses with the Eiband whole-body acceleration } \\
\text { tolerance curve. }\end{array}$} \\
\hline \multirow{2}{*}{\multicolumn{4}{|c|}{$\begin{array}{l}\text { 14. SUBJECT TERMS } \\
\text { Hybrid II } 50 \text { th percentile male ATD, Anthropomorphic Test Dummy (ATD), full-scale } \\
\text { aircraft crash testing, crashworthiness, prediction methods }\end{array}$}} & $\begin{array}{l}\text { 15. NUMBER OF PAGES } \\
22\end{array}$ \\
\hline & & & & 16. PRICE CODE \\
\hline $\begin{array}{l}\text { 17. SECURITY CLASSIFICATION } \\
\text { OF REPORT } \\
\text { Unclassified }\end{array}$ & $\begin{array}{l}\text { 18. SECURITY CLASSIFICATION } \\
\text { OF THIS PAGE } \\
\text { Unclassified }\end{array}$ & $\begin{array}{l}\text { 19. SECURITY CLAS } \\
\text { OF ABSTRACT } \\
\text { Unclassified }\end{array}$ & IFICATION & $\begin{array}{l}\text { 20. LIMITATION } \\
\text { OF ABSTRACT } \\
\text { UL }\end{array}$ \\
\hline NSN 7540-01-28 & & & & $\begin{array}{l}\text { Standard Form } 298 \text { (Rev. 2-89) } \\
\text { Prescribed by ANSI Std. Z39-18 } \\
298-102\end{array}$ \\
\hline
\end{tabular}

